\title{
PENGARUH INDUKSI DAN ZAT PENGATUR TUMBUH TERHADAP PERTUMBUHAN STEK PUCUK KAYU PUTIH (MELALEUCA CAJUPUTI)
}

\author{
Judul Bahasa Inggris \\ (Times New Roman, 12, Capitalize Each Word, Bold, Italic, Center, Spasi 1,25) \\ Tetty Sriwahyuni \\ Perum Perhutani, Jl. Soekarno Hatta No 628 KM 14 Bandung 40292, Telp : \\ (022) 7802871; Fax : (022) 7802972
}

\section{Diterima 15 Februari 2018/Disetujui 1 Maret 2018}

\begin{abstract}
ABSTRAK
The cutting shoot is one of fast growing Malalueca cajuputi seedling. The cutting shoot used from plantation and cajuputi seeds in induction shed. Then, to fast root induction on the cutting shoot must be special treatment is giving hormone from outside. Giving hormonal in Perum Perhutani by IBA (Indole Butyric Acid), but IBA is one of hazard and toxic substances (B3) and not ecofriendly. The object of studies to prove the induction effect on the growth of cajuputi cuttings shoot, the influence of IBA hormone and natural hormone extract of onion to growth of cajuputi cuttings shoot, and determine the best of hormone to growth of cajuputi cutting shoot. Data collected by measuring height of the cajuputi cuttings shoot from the base of stem which has been marked up to the tip of shoots. The measurement of height of cajuputi cutting shoot was repeated 6 (six) times for 90 days so that measurement was done every 15 days. Besides that, there is addition of leaf number since cuttings planted up to 90 HST and root appearance at each treatment. The result of research IBA gives the best growth effect for shoots from Induction that is the highest height compared with other hormones. So this study recommended using shoots of induction with IBA hormone to best growth and eco-friendly.
\end{abstract}

Keywords: Malaluca cajuputi, induction, Indole Butyric Acid

\section{PENDAHULUAN}

Paradigma baru pembangunan kehutanan saat ini melihat kawasan hutan secara utuh sebagai sebuah sistem sumberdaya multi fungsi dan memuat banyak 
kepentingan. Pandangan hasil hutan hanya sebatas kayu sudah tidak berlaku lagi. Dengan kata lain, hasil hutan bukan kayu (HHBK) pun menjadi komponen penting dari kehidupan masyarakat sekitar hutan, dimana hasil hutan ini merupakan sumber daya kawasan yang memiliki keunggulan komparatif dan paling menyentuh kehidupan masyarakat sekitar hutan. (Sumadiwangsa dan Setyawan, 2005)

Salah satu produk unggulan HHBK yang telah dikenal secara luas oleh masyarakat Indonesia adalah minyak kayu putih (Melaleuca cajuputi), Minyak kayu putih merupakan salah satu sumber daya hutan yang memiliki potensi untuk menjadi sumber pendapatan non kayu. Minyak kayu putih termasuk komoditi HHBK kelompok minyak atsiri yang dihasilkan dari hasil penyulingan daun dan ranting kayu putih.

Tanaman kayu putih banyak terdapat di Jawa dan di Kepulauan Maluku. Di Jawa, hutan tanaman kayu putih selama ini dikelola oleh Perum Perhutani baik di Jawa Tengah, Jawa Timur maupun Jawa Barat (Kartikawati et al., 2014). Perum Perhutani mengelola kayu putih seluas $17.826,1$ ha yang terdapat di beberapa wilayah KPH yaitu : KPH Gundih, KPH Telawa, KPH Banyumas Barat, KPH Surakarta, KPH Madiun, KPH Pasuruan, KPH Mojokerto, KPH Tuban, KPH Madura, KPH Nganjuk, KPH Indramayu, KPH Purwakarta dan KPH Kuningan (Wibowo dan Susanto, 2014).

Secara garis besar, produk-produk Perum Perhutani dapat dibagi menjadi 3 segmen, yaitu segmen kayu tebangan (kayu bulat), industri kayu (kayu olahan) dan hasil hutan lainnya (HHBK). Pada tahun 2013, terjadi perubahan prosentase dari kontribusi masing-masing segmen, yaitu kayu bulat $42 \%$, kayu olahan $8 \%$ dan hasil hutan lainnya 50\%, dimana untuk pertama kalinya segmen hasil hutan lainnya menyamai jumlah dari segmen kayu dan segmen kayu olahan. Menurut Sekretaris Direksi Perum Perhutani (2013), dimasa mendatang keuntungan Perum Perhutani dominasinya akan bergeser ke non kayu. Pada tahun 2014 komposisi produksi kayu adalah $45 \%$ dan non kayu $55 \%$.

Untuk meningkatkan produk non kayu dan menyadari arti penting kayu putih yang merupakan komoditas non kayu ke dua setelah gondorukem-terpentin di Perum Perhutani, maka kebijakan manajemen Perum Perhutani telah mencanangkan menanam tanaman kayu putih dengan basis genetik unggul. Rencana penambahan luas tanaman kayu putih Perum Perhutani tahun 2015 seluas 9.998 ha, dimana luas tanaman kayu putih Divisi Regional Jawa Barat dan Banten seluas 4.310 ha dengan kebutuhan bibit kayu putih sebanyak 15.865.861 plances (Perum Perhutani, 2015). 
Untuk mempercepat pencapaian pemenuhan target bibit kayu putih siap tanam, digunakan teknik perbanyakan stek pucuk yang berasal dari bibit kayu putih yang berada di bedeng induksi (asal induksi) selain stek pucuk yang berasal dari kebun pangkas. Selanjutnya untuk mempercepat induksi akar pada stek diperlukan perlakuan khusus yaitu dengan pemberian hormon dari luar, yang diterapkan di Perum Perhutani saat ini dengan menggunakan IBA (Indole Butyric Acid). IBA termasuk bahan berbahaya dan beracun (B3), dalam prinsip dampak pada lingkungan hidup yang semestinya pemanfaatan hutan ramah lingkungan sehingga perlu mencari alternatif penggunaan hormon lain sebagai pengganti IBA.

Menurut Setyowati (2004), beberapa zat pengatur tumbuh alami digunakan dalam pertumbuhan stek akar tanaman. Zat pengatur tumbuh tersebut antara lain ekstrak bawang merah (Allium cepa) sebagai sumber hormon auksin dan air kelapa muda sebagai sumber hormon sitokinin. Ekstrak bawang merah mengandung senyawa allithiamin yang dapat mempengaruhi proses fisiologis tanaman. Berdasarkan uraian diatas, maka penelitian tentang pengaruh induksi dan penggunaan zat pengatur tumbuh terhadap pertumbuhan stek pucuk kayu putih sampai dengan umur bibit siap tanam layak dilakukan. Penelitian ini bertujuan untuk membuktikan bahwa induksi dan hormon berpengaruh terhadap pertumbuhan stek pucuk kayu putih dan membuktikan bahwa adanya interaksi antara induksi dan hormon yang digunakan terhadap pertmbuhan stek pucuk kayu putih.

\section{METODOLOGI PENELITIAN}

Penelitian dilaksanakan di lokasi persemaian Perum Perhutani petak 21 RPH Bantar Panjang BKPH Ciledug KPH Kuningan Divisi Regional Jawa Barat dan Banten. Waktu pelaksanaan penelitian pada bulan September sampai bulan Desember 2015. Alat yang digunakan dalam penelitian adalah : Gunting pangkas, Ember plastic, Bak plastic, Polybag transparan ukuran panjang $15 \mathrm{~cm}$, lebar 10 $\mathrm{cm}$ dan tebal 0,05 cm, Sendok, Bedeng sungkup, Gelas Ukur, Blender, Hand Sprayer, Selotip warna, Alat tulis menulis (spidol permanen, kertas, ballpoint dan mistar ukur). Bahan yang digunakan adalah Media semai, Stek pucuk kayu putih , Air/aquades, Larutan IBA, dan Ekstrak bawang merah.

Pengumpulan data diperoleh dari hasil penelitian yang dilakukan terhadap penambahan tinggi stek pucuk kayu putih sejak ditanam di polybag sampai dengan bibit umur siap tanam (90 hst), dengan melakukan pengukuran tinggi stek pucuk kayu putih diulang sebanyak 6 (enam) kali selama 90 hari sehingga pengukuran dilakukan setiap 15 hari. Selain itu dilakukan juga penelitan 
penambahan jumlah daun sejak stek ditanaman sampai dengan 90 hst dan penampakan akar pada masing-masing perlakuan.

Pengukuran tinggi stek pucuk kayu putih dilakukan dari pangkal batang yang telah ditandai sampai dengan ujung stek pucuk, penambahan jumlah daun dilakukan dengan menghitung jumlah daun yang telah mekar sempurna pada saat awal penancapan stek pucuk dan pada akhir penelitian, sedangkan penampakan akar dengan melakukan pengukuran tinggi akar dan menghitung jumlah akar dengan mengambil salah satu stek dari masing-masing perlakuan setelah penelitian berakhir pada 90 hst.

Batasan variabel-variabel penelitian sebagai berikut: 1) Pengaruh berarti respons, tanggapan atau reaksi adalah reaksi yang dihasilkan dari stek pucuk kayu putih setelah diberikan beberapa perlakuan yaitu asal stek pucuk dan pemberian zat pengatur tumbuh atau hormon. 2) Induksi adalah perangsangan atau menumbuhkan akar pada tanaman, yaitu stek pucuk yang diambil dari bibit yang berada di dalam bedeng induksi (bedeng persemaian yang ditutupi oleh sungkup) sebagai tempat untuk meletakkan stek pucuk yang telah ditanam di dalam polybag yang berfungsi sebagai tempat untuk merangsang pertumbuhan akar sebelum dipindah ke bedeng aklimatisasi. 3) Zat Pengatur Tumbuh (ZPT) pada tanaman adalah senyawa organik yang bukan termasuk unsur hara, yang dalam jumlah sedikit dapat mendukung (promote), menghambat (inhibit) dan dapat merubah proses fisiologi tumbuhan Adapaun ZPT yang digunakan dalam penelitian ini adalah IBA (Indole Butyric Acid) dan Ekstrak Bawang Merah. 4) Pertumbuhan adalah proses pertambahan ukuran yang tidak dapat kembali (irreversible), yang meliputi pertambahan volume dan pertambahan massa. Selain disebabkan pertambahan ukuran sel, pertumbuhan juga terjadi karena pertambahan jumlah sel. Dalam penelitian ini parameter pertumbuhan yang diukur adalah penambahan tinggi stek pucuk. Selain itu dilakukan pula penelitian terhadap penambahan jumlah daun dan kondisi akar sebagai data penunjang. 5) Stek Pucuk Kayu Putih Salah adalah salah satu teknik perbanyakan tanaman secara vegetatif yang dilakukan dengan memanfaatkan bagian-bagian tanaman bagian ujung atau pucuk tanaman. Stek pucuk dalam penelitian ini berasal dari kebun pangkas dan dari bibit asal stek pucuk yang berada dalam bedeng induksi. Bagan alur prosedur penelitian sebagaimana layout dibawah ini : 


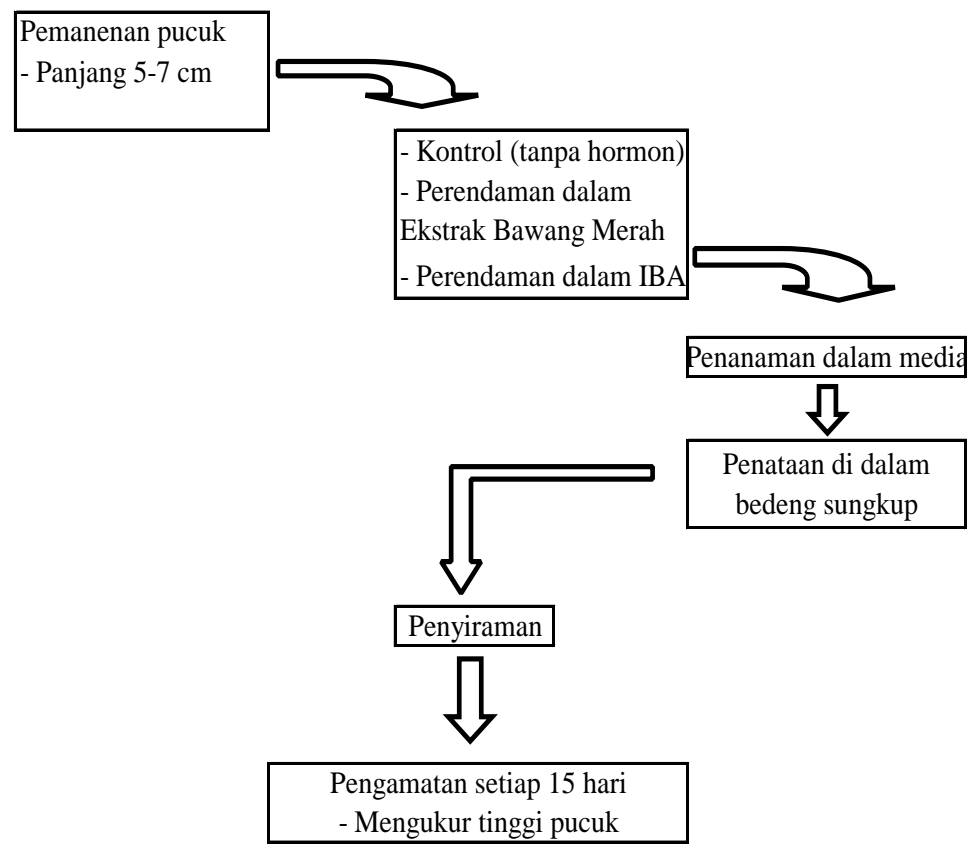

Gambar 1. Bagan Alir Prosedur Penelitian

Persiapan stek pucuk dengan melakukan pemanenan pucuk kayu putih pagi atau sore hari yang diambil dari dua tempat yang berbeda yaitu kebun pangkas klon 71 dan pucuk dari bibit yang berasal dalam bedeng induksi dengan klon yang sama, ukuran tinggi 5-7 cm masing-masing sebanyak 30 pucuk. Kebun pangkas dibangun di sekitar lokasi persemaian untuk menyediakan bahan stek pucuk. Iklim di lokasi ini minimal tipe $\mathrm{D}$, suhu $21-30^{\circ} \mathrm{C}$, curah hujan 800-1.600 $\mathrm{mm} /$ tahun. Kebun pangkas adalah sumber benih yang dibangun dari bahan vegetative yang berasal dari klon unggul yang memiliki kriteria antara lain produktif, rendemen minyak kayu putih yang tinggi dan tahan hama penyakit berdasarkan hasil uji klon untuk memproduksi materi vegetative.

Persiapan Zat Pengatur Tumbuhan dilakukan dengan beberapa tahapan, yaitu:

a. Hormon Alami Ekstrak Bawang Merah diperoleh dengan menumbuk atau menghancurkan umbi bawang merah sebanyak 250 gr menggunakan blender sampai hancur dan halus, kemudian diperas. Cairan bawang merah hasil perasan disaring agar terpisah dengan ampasnya dan dilarutkan dalam 1 liter air. b. Hormon IBA (Indole Butyric Acid), sebanyak 0,02 gr dilarutkan dalam 1 liter air (20 ppm). c. Persiapan Media, yang digunakan adalah topsoil : kompos/pupuk kandang : pasir dengan perbandingan (3:1:1). Media dimasukan dalam polybag yang berwarna jernih/transparan (ukuran panjang $=15 \mathrm{~cm}$, lebar $=10 \mathrm{~cm}$, tebal $=$ $0,005 \mathrm{~cm}$ ), agar saat keluar akar atau perkembangan akar dapat dilihat secara 
visual (langsung). Polybag yang sudah terisi media ditata dalam bedeng induksi yang telah diacak. Penempatannya. Setiap polybag diberi label sesuai perlakuan masing-masing. d. Aplikasi hormone, dilakukan dengan cara stek pucuk kayu putih direndam hormon bawang merah dan IBA dengan lama perendaman selama 15 menit. e. Penanaman stek dalam media, ditanam dalam polybag yang telah disediakan sedalam $2 \mathrm{~cm}$ dan posisi pucuk lurus ke atas, setelah itu dilakukan penyiraman menggunakan sprayer, sehingga butiran air siraman mengkabut. f. Pemeliharaan, meliputi penyiraman yang dilakukan 2 kali sehari atau melihat kondisi kelembaban di bedeng dan penyiangan gulma serta pengendalian hama dan penyakit.

Rancangan penelitian dan analisis data, dengan pendekatan matematis (analisis sidik ragam) dan melalui pengamatan langsung dari hasil pengukuran tinggi stek pucuk kayu putih. Analisis sidik ragam yang digunakan adalah Rancangan Acak Lengkap (RAL) Faktorial dengan faktor perlakuan pertama adalah asal stek pucuk dari kebun pangkas dan dari bedeng induksi, faktor perlakuan kedua adalah jenis hormon yang digunakan yaitu hormon alami ekstrak bawang merah, larutan IBA dan kontrol (tanpa pemberian hormon) dimana masing-masing perlakuan diulang sebanyak 10 kali sehingga berjumlah 60 unit percobaan. Analisis Sidik Ragam terhadap data diolah dengan menggunakan Rancangan Acak Lengkap Faktorial dengan rancangan model matematisnya adalah :

Keterangan :

$$
Y i j k=\mu+\alpha i+\beta j+\alpha \beta i j+\varepsilon i j k
$$

Yijk $\quad$ : respon pengamatan perlakuan pada factor $\alpha$ ke-i dan $\beta$ ke-j pada ulangan ke $-\mathrm{k}$

$\mu \quad$ : rata - rata umum/nilai tengah

ai $\quad$ : pengaruh perlakuan $\alpha$ pada taraf $\mathrm{ke}-\mathrm{i}$

$\beta \mathrm{j} \quad$ : pengaruh perlakuan $\beta$ pada taraf $\mathrm{ke}-\mathrm{j}$

$\alpha \beta \mathrm{ij} \quad$ : pengaruh interaksi factor $\alpha$ dan $\beta$

cijk : pengaruh galat

Bila pada analisis sidik ragam menunjukkan signifikansi maka analisis data dilanjutkan dengan uji LSD 5\%. Data hasil pengamatan dihitung dan dianalisis menggunakan IBM SPSS Statistik 24. Penataan polybag dalam bedeng induksi dapat dilihat pada gambar 2 di bawah ini. 


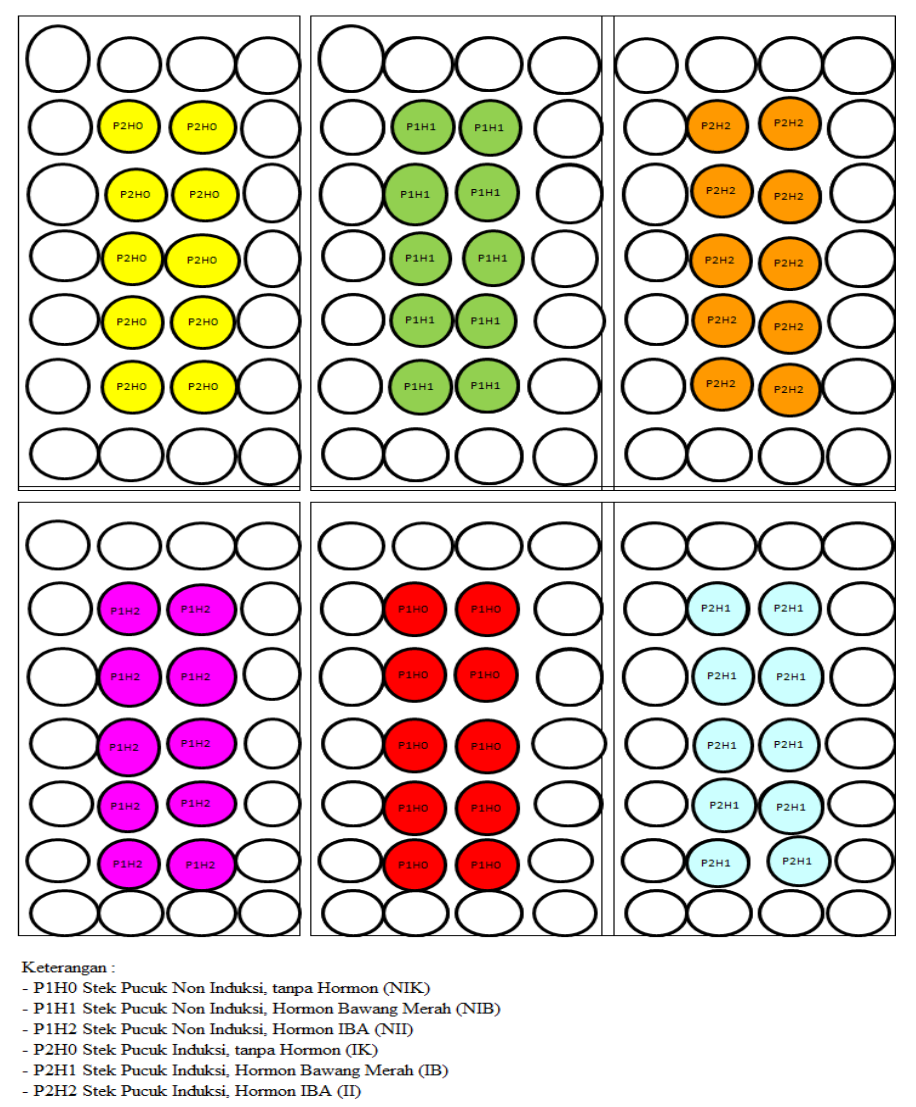

Gambar 2. Penataan Polybag dalam Bedeng Induksi

\section{HASIL DAN PEMBAHASAN}

\section{HASIL}

Data hasil penelitian stek pucuk kayu putih dengan perlakuan-perlakuan kontrol (K), ekstrak bawang merah (B) dan larutan IBA (I) diperoleh hasil penambahan tinggi stek pucuk kayu putih pada setiap kali pengukuran terdapat pada Tabel 1 sampai Tabel 8. Berdasarkan perolehan data hasil penelitian yaitu penambahan tinggi, jumlah daun dan penampakan akar, dan berdasarkan analisis pengujian statistik ternyata hasil terbaik didapat pada stek pucuk asal induksi dengan perlakuan perendaman dalam larutan IBA.

Tabel 1 menunjukkan penambahan tinggi stek pucuk selama 15 hari adalah $1,25 \mathrm{~cm}$ dengan stek pucuk asal kebun pangkas pada perlakuan kontrol, stek pucuk asal kebun pangkas pada perlakuan bawang merah adalah $1,45 \mathrm{~cm}$, stek pucuk asal kebun pangkas pada perlakuan IBA adalah 2,45 cm, stek pucuk asal bedeng induksi pada perlakuan kontrol adalah 1,65 cm, stek pucuk asal bedeng induksi pada perlakuan bawang merah adalah 2,65 cm dan stek pucuk asal bedeng induksi pada perlakuan IBA adalah $2,8 \mathrm{~cm}$. 
Tabel 1. Rata-rata penambahan tinggi stek pucuk kayu putih $15 \mathrm{hst}$

\begin{tabular}{lcl}
\hline \multicolumn{1}{c}{ Perlakuan } & \multicolumn{2}{c}{ Rata-rata Tinggi $(\mathbf{C m})$} \\
\hline Non Induksi Kontrol & 1,25 & $\mathrm{~b}$ \\
Non Induksi Bawang Merah & 1,45 & $\mathrm{~b}$ \\
Non Induksi IBA & 2,45 & $\mathrm{a}$ \\
\hline \multicolumn{2}{c}{ Bedeng } & $\mathrm{b}$ \\
\hline Induksi Kontrol & 1,65 & $\mathrm{a}$ \\
Induksi Bawang Merah & 2,65 & $\mathrm{a}$ \\
Induksi IBA & 2,80 &
\end{tabular}

Keterangan: Angka rata-rata perlakuan yang diikuti oleh huruf yang sama di kolom yang sama, tidak berbeda nyata menurut uji LSD pada $\alpha$.

Ketiga hasil perlakuan di atas dapat disimpulkan bahwa stek pucuk dari bedeng induksi dengan diberikan perlakuan IBA memberikan penambahan tinggi stek pucuk kayu putih yang tertinggi, tetapi tidak berbeda nyata dengan stek pucuk berasal dari kebun pangkas dengan perlakuan IBA dan stek pucuk asal bedeng induksi dengan perlakuan bawang merah.

Tabel 2. Rata-rata penambahan tinggi stek pucuk kayu putih $30 \mathrm{hst}$

\begin{tabular}{lcc}
\hline \multicolumn{1}{c}{ Perlakuan } & Rata-rata Tinggi $(\mathbf{C m})$ \\
\hline Non Induksi Kontrol & 3,08 & $\mathrm{c}$ \\
Non Induksi Bawang Merah & 4,55 & $\mathrm{c}$ \\
Non Induksi IBA & 5,40 & $\mathrm{c}$ \\
\hline \multicolumn{2}{c}{ Bedeng } & \\
\hline Induksi Kontrol & 9,30 & $\mathrm{~b}$ \\
Induksi Bawang Merah & 7,70 & $\mathrm{~b}$ \\
Induksi IBA & 11,60 & $\mathrm{a}$ \\
\hline
\end{tabular}

Sumber data : Hasil Penelitian

Keterangan: Angka rata-rata perlakuan yang diikuti oleh huruf yang sama di kolom yang sama, tidak berbeda nyata menurut uji $L S D$ pada $\alpha$.

Tabel 2 di atas menunjukkan penambahan tinggi stek pucuk selama 30 hari adalah 3,08 $\mathrm{cm}$ dengan stek pucuk asal kebun pangkas pada perlakuan kontrol, stek pucuk asal kebun pangkas pada perlakuan bawang merah adalah $4,55 \mathrm{~cm}$, stek pucuk asal kebun pangkas pada perlakuan IBA adalah $5,4 \mathrm{~cm}$, stek pucuk asal bedeng induksi pada perlakuan control adalah $9,30 \mathrm{~cm}$, stek pucuk asal bedeng induksi pada perlakuan bawang merah adalah 7,70 $\mathrm{cm}$ dan stek pucuk asal bedeng induksi pada perlakuan IBA adalah $11,6 \mathrm{~cm}$.

Ketiga hasil perlakuan di atas dapat disimpulkan bahwa stek pucuk berasal dari bedeng induksi dengan diberikan perlakuan IBA memberikan penambahan 
tinggi stek pucuk kayu putih yang tertinggi. Stek pucuk berasal dari bedeng induksi perlakuan kontrol tidak berbeda nyata dengan stek pucuk berasal dari bedeng induksi dengan perlakuan bawang merah. Sedangkan stek pucuk berasal dari kebun pangkas dengan perlakuan kontrol, bawang merah dan IBA semuanya tidak berbeda nyata.

Tabel 3 menunjukkan penambahan tinggi stek pucuk selama 45 hari adalah $6,30 \mathrm{~cm}$ dengan stek pucuk asal kebun pangkas pada perlakuan kontrol, stek pucuk asal kebun pangkas pada perlakuan bawang merah adalah $8,75 \mathrm{~cm}$, stek pucuk asal kebun pangkas pada perlakuan IBA adalah $8,25 \mathrm{~cm}$, stek pucuk asal bedeng induksi pada perlakuan control adalah $18,15 \mathrm{~cm}$, stek pucuk asal bedeng induksi pada perlakuan bawang merah adalah $18,6 \mathrm{~cm}$ dan stek pucuk asal bedeng induksi pada perlakuan IBA adalah $25,28 \mathrm{~cm}$.

Tabel 3. Rata-rata penambahan tinggi stek pucuk kayu putih 45 hst

\begin{tabular}{lrl}
\hline \multicolumn{1}{c}{ Perlakuan } & \multicolumn{2}{c}{ Rata-rata Tinggi $(\mathbf{C m})$} \\
\hline & Kebun Pangkas & \\
\hline Non Induksi Kontrol & 6,30 & $\mathrm{c}$ \\
Non Induksi Bawang Merah & 8,75 & $\mathrm{c}$ \\
Non Induksi IBA & 8,25 & $\mathrm{c}$ \\
\hline \multicolumn{2}{c}{ Bedeng } & \\
\hline Induksi Kontrol & 18,15 & $\mathrm{~b}$ \\
Induksi Bawang Merah & 18,60 & $\mathrm{~b}$ \\
Induksi IBA & 25,28 & $\mathrm{a}$ \\
\hline Sumber data : Hasil Penelitian & &
\end{tabular}

Keterangan : Angka rata-rata perlakuan yang diikuti oleh huruf yang sama di kolom yang sama, tidak berbeda nyata menurut uji LSD pada $\alpha$.

Ketiga hasil perlakuan di atas dapat disimpulkan bahwa stek pucuk berasal dari bedeng induksi dengan diberikan perlakuan IBA memberikan penambahan tinggi stek pucuk kayu putih yang tertinggi. Stek pucuk berasal dari bedeng induksi perlakuan kontrol tidak berbeda nyata dengan stek pucuk berasal dari bedeng induksi dengan perlakuan bawang merah. Sedangkan stek pucuk berasal dari kebun pangkas dengan perlakuan kontrol, bawang merah dan IBA semuanya tidak berbeda nyata.

Tabel 4 menunjukkan penambahan tinggi stek pucuk selama 60 hari adalah $8,75 \mathrm{~cm}$ dengan stek pucuk asal kebun pangkas pada perlakuan kontrol, stek pucuk asal kebun pangkas pada perlakuan bawang merah adalah 11,45 cm, stek pucuk asal kebun pangkas pada perlakuan IBA adalah $11,15 \mathrm{~cm}$, stek pucuk asal bedeng induksi pada perlakuan control adalah $25,95 \mathrm{~cm}$, stek pucuk asal bedeng induksi pada perlakuan bawang merah adalah $24,3 \mathrm{~cm}$ dan stek pucuk asal bedeng induksi pada perlakuan IBA adalah $29,75 \mathrm{~cm}$. 
Tabel 4. Rata-rata penambahan tinggi stek pucuk kayu putih 60 hst

\begin{tabular}{lcl}
\hline \multicolumn{1}{c}{ Perlakuan } & Rata-rata Tinggi (Cm) \\
\hline Non Induksi Kontrol & 8,75 & $\mathrm{c}$ \\
Non Induksi Bawang Merah & 11,45 & $\mathrm{c}$ \\
Non Induksi IBA & 11,15 & $\mathrm{c}$ \\
\hline \multicolumn{2}{c}{ Bedeng } & \\
\hline Induksi Kontrol & 25,95 & $\mathrm{~b}$ \\
Induksi Bawang Merah & 24,30 & $\mathrm{~b}$ \\
Induksi IBA & 29,75 & $\mathrm{a}$ \\
\hline Sumber data $:$ Hasil Penelitian & &
\end{tabular}

Sumber data : Hasil Penelitian

Keterangan : Angka rata-rata perlakuan yang diikuti oleh huruf yang sama di kolom yang sama, tidak berbeda nyata menurut uji LSD pada $\alpha$.

Tabel 5. Rata-rata penambahan tinggi stek pucuk kayu putih 75 hst

\begin{tabular}{lcl}
\hline \multicolumn{1}{c}{ Perlakuan } & Rata-rata Tinggi $(\mathbf{C m})$ \\
\hline Non Induksi Kontrol & 11,50 & \\
Non Induksi Bawang Merah & 13,50 & $\mathrm{c}$ \\
Non Induksi IBA & 14,25 & $\mathrm{c}$ \\
& Bedeng & $\mathrm{c}$ \\
Induksi Kontrol & 32,70 & $\mathrm{~b}$ \\
Induksi Bawang Merah & 32,35 & $\mathrm{~b}$ \\
Induksi IBA & 38,00 & $\mathrm{a}$ \\
Sumber data : Hasil Penelitian & &
\end{tabular}

Keterangan : Angka rata-rata perlakuan yang diikuti oleh huruf yang sama di kolom yang sama, tidak berbeda nyata menurut uji LSD pada $\alpha$.

Ketiga hasil perlakuan di atas dapat disimpulkan bahwa stek pucuk berasal dari bedeng induksi dengan diberikan perlakuan IBA memberikan penambahan tinggi stek pucuk kayu putih yang tertinggi. Stek pucuk berasal dari bedeng induksi perlakuan kontrol tidak berbeda nyata dengan stek pucuk berasal dari bedeng induksi dengan perlakuan bawang merah. Sedangkan stek pucuk berasal dari kebun pangkas dengan perlakuan kontrol, bawang merah dan IBA semuanya tidak berbeda nyata.

Tabel 5 menunjukkan penambahan tinggi stek pucuk selama 75 hari adalah $11,5 \mathrm{~cm}$ dengan stek pucuk asal kebun pangkas pada perlakuan kontrol, stek pucuk asal kebun pangkas pada perlakuan bawang merah adalah 13,5 cm, stek pucuk asal kebun pangkas pada perlakuan IBA adalah $14,25 \mathrm{~cm}$, stek pucuk asal bedeng induksi pada perlakuan control adalah $32,70 \mathrm{~cm}$, stek pucuk asal bedeng 
induksi pada perlakuan bawang merah adalah $32,35 \mathrm{~cm}$ dan stek pucuk asal bedeng induksi pada perlakuan IBA adalah $38,00 \mathrm{~cm}$.

Dari ketiga hasil perlakuan diatas dapat disimpulkan bahwa stek pucuk berasal dari bedeng induksi dengan diberikan perlakuan IBA memberikan penambahan tinggi stek pucuk kayu putih yang tertinggi. Stek pucuk berasal dari bedeng induksi perlakuan kontrol tidak berbeda nyata dengan stek pucuk berasal dari bedeng induksi dengan perlakuan bawang merah. Sedangkan stek pucuk berasal dari kebun pangkas dengan perlakuan kontrol, bawang merah dan IBA semuanya tidak berbeda nyata.

Tabel 6. Rata-rata penambahan tinggi stek pucuk kayu putih 90 hst

\begin{tabular}{lcl}
\hline \multicolumn{1}{c}{ Perlakuan } & Rata-rata Tinggi $(\mathbf{C m})$ \\
\hline Non Induksi Kontrol & 15,50 & $\mathrm{c}$ \\
Non Induksi Bawang Merah & 16,70 & $\mathrm{c}$ \\
Non Induksi IBA & 17,90 & $\mathrm{c}$ \\
\hline \multicolumn{2}{c}{ Bedeng } & $\mathrm{b}$ \\
\hline Induksi Kontrol & 38,80 & $\mathrm{~b}$ \\
Induksi Bawang Merah & 41,00 & $\mathrm{a}$ \\
Induksi IBA & 45,60 & \\
\hline
\end{tabular}

Sumber data : Hasil Penelitian

Keterangan: Angka rata-rata perlakuan yang diikuti oleh huruf yang sama di kolom yang sama, tidak berbeda nyata menurut uji LSD pada $\alpha$

Tabel 6 menunjukkan penambahan tinggi stek pucuk selama 90 hari adalah $15,5 \mathrm{~cm}$ dengan stek pucuk asal kebun pangkas pada perlakuan kontrol, stek pucuk asal kebun pangkas pada perlakuan bawang merah adalah $16,7 \mathrm{~cm}$, stek pucuk asal kebun pangkas pada perlakuan IBA adalah $17,90 \mathrm{~cm}$, stek pucuk asal bedeng induksi pada perlakuan control adalah $38,80 \mathrm{~cm}$, stek pucuk asal bedeng induksi pada perlakuan bawang merah adalah $41,00 \mathrm{~cm}$ dan stek pucuk asal bedeng induksi pada perlakuan IBA adalah $45,60 \mathrm{~cm}$.

Dari ketiga hasil perlakuan diatas dapat disimpulkan bahwa stek pucuk berasal dari bedeng induksi dengan diberikan perlakuan IBA memberikan penambahan tinggi stek pucuk kayu putih yang tertinggi. Stek pucuk berasal dari bedeng induksi perlakuan kontrol tidak berbeda nyata dengan stek pucuk berasal dari bedeng induksi dengan perlakuan bawang merah. Sedangkan stek pucuk berasal dari kebun pangkas dengan perlakuan kontrol, bawang merah dan IBA semuanya tidak berbeda nyata.

Tabel 7. Rata-rata penambahan daun stek pucuk kayu putih 90 hst 


\begin{tabular}{lcc}
\hline \multicolumn{1}{c}{ Perlakuan } & Rata-rata Daun (Helai) \\
\hline & Kebun Pangkas & \\
\hline Non Induksi Kontrol & 34,30 & $\mathrm{~b}$ \\
Non Induksi Bawang Merah & 33,70 & $\mathrm{~b}$ \\
Non Induksi IBA & 34,20 & $\mathrm{~b}$ \\
\hline \multicolumn{2}{c}{ Bedeng } & $\mathrm{a}$ \\
\hline Induksi Kontrol & 67,60 & $\mathrm{a}$ \\
Induksi Bawang Merah & 69,10 & $\mathrm{a}$ \\
Induksi IBA & 69,30 &
\end{tabular}

Sumber data : Hasil Penelitian

Keterangan : Angka rata-rata perlakuan yang diikuti oleh huruf yang sama di kolom yang sama, tidak berbeda nyata menurut uji LSD pada $\alpha$

Tabel 7 di atas terlihat rata-rata jumlah penambahan daun pada stek pucuk kayu putih selama 90 hari adalah 34,30 helai dengan stek pucuk asal kebun pangkas pada perlakuan kontrol, stek pucuk asal kebun pangkas pada perlakuan bawang merah adalah 33,70 helai, stek pucuk asal kebun pangkas pada perlakuan IBA adalah 34,20 helai, stek pucuk asal bedeng induksi pada perlakuan kontrol adalah 67,60 helai, stek pucuk asal bedeng induksi pada perlakuan bawang merah adalah 69,10 helai dan stek pucuk asal bedeng induksi pada perlakuan IBA adalah 69,30 helai.

Dari ketiga hasil perlakuan diatas dapat disimpulkan bahwa stek pucuk berasal dari bedeng induksi dengan diberikan perlakuan IBA memberikan penambahan jumlah daun terbanyak, tetapi tidak berbeda nyata dengan stek pucuk asal bedeng induksi dengan perlakuan kontrol dan bawang merah. Stek pucuk berasal dari kebun pangkas perlakuan kontrol tidak berbeda nyata dengan stek pucuk berasal dari bedeng induksi dengan perlakuan bawang merah dan IBA.

Akar pertama rata-rata keluar pada 15 hst. Tabel 8 menunjukkan jumlah akar rambut terbanyak pada stek pucuk kayu putih selama 90 hari adalah 7 helai dengan panjang akar $21 \mathrm{~cm}$ dan tinggi stek pucuk $54 \mathrm{~cm}$, terdapat pada stek pucuk asal induksi dengan pemberian hormon IBA. Stek pucuk dengan perlakuan hormon bawang merah memiliki bulu akar yang lebih banyak daripada stek pucuk asal induksi. Sedangkan pada stek pucuk asal induksi memiliki jumlah akar rambut lebih banyak daripada stek pucuk asal kebun pangkas, sebagaima gambar terlampir pada lampiran 2 Dokumentasi Penelitian. Penelitian akar tidak dianalisis secara statistik karena data yang diambil tidak dari semua stek pucuk tetapi hanya diambil satu stek pucuk dari masing-masing perlakuan sehingga data tidak terpenuhi.

Tabel 8. Kondisi Akar Stek Pucuk Kayu Putih 90 hst. 


\begin{tabular}{|c|c|c|}
\hline Perlakuan & $\begin{array}{l}\text { Jumlah akar } \\
\text { rambut (helai) }\end{array}$ & $\begin{array}{r}\text { Panjang } \\
\text { Akar }(\mathrm{cm})\end{array}$ \\
\hline \multicolumn{3}{|c|}{ Kebun Pangkas } \\
\hline Non Induksi Kontrol & 3 & 14 \\
\hline Non Induksi Bawang Merah & 3 & 15 \\
\hline Non Induksi IBA & 5 & 17 \\
\hline \multicolumn{3}{|c|}{ Bedeng } \\
\hline Induksi Kontrol & 4 & 17 \\
\hline Induksi Bawang Merah & 6 & 18 \\
\hline Induksi IBA & 7 & 21 \\
\hline
\end{tabular}

Tabel 1 sampai 8 terlihat bahwa pada stek pucuk asal induksi penambahan tingginya lebih tinggi dan berbeda nyata dibandingkan dengan stek pucuk asal kebun pangkas karena stek pucuk asal induksi pada saat penyimpanan di bedeng induksi guna merangsang pertumbuhan akar telah beradaptasi dengan kondisi suhu pada bedeng induksi asal stek pucuk tersebut. Stek pucuk asal kebun pangkas perlu adaptasi terlebih dahulu dengan kondisi suhu pada saat diletakan di dalam bedeng induksi, sehingga pertumbuhannya lebih lambat.

Selain asal stek pucuk dari bedeng induksi, perlakuan hormon IBA memberikan hasil terbaik dalam pertumbuhan stek pucuk pada penelitian ini. Pada stek pucuk kayu putih 90 hst, perendaman dalam larutan IBA konsentrasi 20 ppm selama 15 menit sudah mampu menghasilkan rata-rata penambahan tinggi terbaik yaitu 45,60 cm, jumlah daun terbanyak rata-rata 69,30 helai, jumlah akar rambut terbanyak 7 helai dan panjang akar terpanjang $21 \mathrm{~cm}$ (table 6, 7 dan 8). Hormon IBA merupakan hormon sintetik golongan auksin yang dapat memacu pertumbuhan akar baru pada potongan stek yang menyebabkan stek pucuk tersebut lebih cepat pertumbuhannya, ditambah faktor keadaan umum lokasi yang mendukung. Dengan semakin cepatnya pembentukan akar dari stek pucuk yang diberikan perlakuan hormon IBA, semakin lebih baik sistem perakarannya sehingga air dan unsur-unsur hara dalam tanah yang diserap stek pucuk akan lebih banyak. Hasil penelitian Omon (2002) menunjukkan bahwa penggunaan IBA menunjukkan pengaruh untuk jumlah akar pada stek tanaman meranti merah (Shorea balangeran (Korth).

Perlakuan pemberian IBA dari hasil pengukuran 15 hst belum terlihat bereaksi, auksin endogen yang terdapat pada stek pucuk kayu putih belum mampu memacu pertumbuhan akar. IBA dalam stek pucuk asal kebun pangkas pada 15 
hst berpengaruh, tetapi dalam pertumbuhan selanjutnya tidak berpengaruh dan terlihat bereaksi secara konstan setelah 30 hst sampai dengan 90 hst.

Selain dipakai untuk merangsang perakaran, hormon IBA juga mempunyai manfaat yang lain seperti menambah daya kecambah, merangsang perkembangan buah, mencegah kerontokan dan pendorong kegiatan cambium (Kusumo, 1984 dalam Irwanto, 2001). Sebagaimana diketahui bahwa auksin adalah jenis hormon penumbuh yang dibuat oleh tanaman dan berfungsi sebagai katalisator dalam metabolisme dan berperan sebagai penyebab perpanjangan sel. IBA paling cocok untuk merangsang aktifitas perakaran, karena kandungan kimianya lebih stabil dan daya kerjanya lebih lama. IBA yang diberikan pada stek pucuk berada di tempat pemberiannya, tidak mudah menyebar ke bagian lain yang akan menghambat perkembangan pertumbuhan pucuk. Dengan semakin cepatnya pembentukan akar dari stek pucuk yang diberikan perlakuan hormon IBA, semakin lebih baik sistim perakarannya sehingga air dan unsur-unsur hara dalam tanah yang diserap stek pucuk akan lebih banyak.

Asal stek pucuk berpengaruh terhadap pertumbuhan tinggi stek pucuk kayu putih, demikian pula dengan perlakuan pemberian hormon IBA pada stek pucuk asal induksi. Ini berarti induksi dan hormon IBA berpengaruh positif dalam pertumbuhan stek pucuk kayu putih. Tetapi pemberian hormon terhadap stek pucuk kayu putih asal kebun pangkas tidak berbeda nyata dengan stek pucuk yang tidak diberikan hormon.

Pada penelitian ini lamanya perendaman stek pucuk kayu putih dalam hormon dilakukan selama 15 menit, hal ini berpengaruh terhadap pertumbuhan. Menurut Panjaitan (2000) dalam Fahmi (2014), tinggi rendahnya hasil dari penggunaan zpt tergantung pada beberapa faktor, salah satu diantaranya adalah lamanya stek direndam dalam larutan. Dalam hasil penelitian Hamzah (2016), menyatakan bahwa perlakuan konsentrasi dan lama perendaman memberikan pengaruh yang berbeda nyata terhadap persentase hidup stek tembesu. Pada konsentrasi IBA 100 ppm perendaman 2 jam dan 3 jam akan menghasilkan persentase stek hidup lebih tinggi dibandingkan dengan lama perendaman 1 jam. Dengan demikian perlu dilakukan penelitian lanjutan terhadap lamanya perendaman stek pucuk kayu putih untuk memperoleh hasil pertumbuhan terbaik.

Pembuatan bibit kayu putih asal stek pucuk di wilayah kerja Perum Perhutani Divisi Regional Jawa Barat dan Banten, selama ini menggunakan perlakuan perendaman dalam larutan IBA konsentrasi 20 ppm selama 15 menit baik terhadap stek pucuk yang berasal dari kebun pangkas ataupun dari bedeng induksi. 
Berdasarkan hasil penelitian, jenis perlakuan IBA terhadap stek pucuk asal kebun pangkas tidak berbeda nyata dengan yang tidak diberikan perlakuan (kontrol), sehingga secara ekonomis untuk stek pucuk yang berasal dari kebun pangkas lebih baik tidak diberikan perlakuan apapun agar tidak mengeluarkan biaya untuk pembelian hormon. Agar diperoleh hasil pertumbuhan stek pucuk kayu putih terbaik disarankan menggunakan stek pucuk asal induksi dengan pemberian hormon IBA dan penggunaan dosis yang tepat supaya tidak banyak terbuang atau efisien sehingga tidak mencemari lingkungan.

Alternatif penggunaan hormon lain sebagai pengganti IBA dalam penelitan ini adalah dengan menggunakan ekstrak bawang merah. Bawang merah mengandung zat pengatur pertumbuhan alami berupa fitohormon auksin dan giberelin. Di dalam ekstrak bawang merah mengandung vitamin B1 (Thiamin) untuk pertumbuhan tunas, riboflavin untuk pertumbuhan, asam nikotinat sebagai koenzim,serta mengandung ZPT auksin dan rhizokalin yang dapat merangsang pertumbuhan akar. Akan tetapi hasil penelitian menunjukkan bahwa perlakuan dengan penggunaan ekstrak bawang merah selama 15 menit pada stek pucuk asal kebun pangkas ataupun induksi tidak berbeda nyata dengan kontrol sehingga secara ekonomis lebih baik tidak diberikan perlakuan apapun agar tidak mengeluarkan biaya untuk pembelian hormon.

\section{KESIMPULAN}

Hasil penelitian diperoleh kesimpulan sebagai berikut :

1. Induksi dan hormon berpengaruh dan interaksi sejak 15 hst sampai dengan 90 hst.

2. Setelah dilakukan penelitian menggunakan hormon ektrak bawang merah dan IBA, ternyata IBA memberikan pengaruh pertumbuhan terbaik untuk stek pucuk asal Induksi, terlihat dari hasil penelitian selama 90 hari. Stek pucuk yang diberikan hormon IBA memiliki tinggi paling tinggi dibanding dengan hormon yang lain.

3. Tidak ada pengaruh interaksi antara hormon dengan asal stek pucuk pada parameter tinggi stek. Dari hasil uji LSD 5\% pada hasil pengukuran tinggi 90 hst diperoleh hasil sign 0,276 menunjukan > 0,05, artinya tidak ada pengaruh karena interaksi hormone dengan asal stek pucuk, walaupun secara sendirisendiri hormon (sign 0,009$)$ da nasal stek pucuk $(0,000)$ memberikan pengaruh yang signifikan. 


\section{DAFTAR PUSTAKA}

Adinugraha, H.A. 2011. Teknik Pembibitan Tanaman Hutan. Balai Besar Penelitian dan Pemuliaan Tanaman Hutan. https://forestryinformation.wordpress.com. Akses 7 Juli 2015.

Aguazen, H. 2009. Respon Pertumbuhan Bibit Stek Lada (Piper nisrum L) Terhadap Pemberian Air Kelapa dan Berbagai Jenis CMA. Kaprodi Agronomi FP Universitas Baturaja dan Alumni Magister Teknologi UNAND. Sumatera Barat.

Agung. 2014. Perlu Strategi Pengembangan HHBK di Hutan Indonesia. Dalam : Seminar Peranan dan Strategi Kebijakan Pemanfaatan Hasil Hutan Bukan Kayu (HHBK) dalam Meningkatkan Daya Guna Wawasan Hutan. Yogyakarta 6 Nopember 2014. Fakultas Kehutanan UGM dan Ditjen BPDAS-PS Kementrian Kehutanan RI.

Astuti, P. 2000. Pengaruh Lama Pengeratan Bahan Stek dan KonsentrasiRootone F Terhadap Pertumbuhan Stek Kopi Robusta (Coffe caphora). www.unmul.ac.id/dat/pub/frontir/puji.pdf . Akses 7 Juli 2015.

Biro Pembinaan SDH. 2015. Petunjuk Pelaksanaan Pengelolaan Tanaman Kayu Putih. Perum Perhutani Divisi Regional Jawa Barat dan Banten. Bandung.

Corryanti. 2014. Ketika Kayu Putih Menjadi Harapan. Majalah BINA, Edisi 04. Juni 2014. Perum Perhutani. Jakarta.

Corryanti.2014. Lagi-lagi Kayu Putih. Majalah BINA. Edisi 09.November 2014.Perum Perhutani. Jakarta.

Permenhut No. P.35/Menhut-II/2007. Tentang Hasil Hutan Bukan Kayu. Departemen Kehutanan Kemenhut. Jakarta.

El Halim, Aulia, B. Pramudityo, R. Setiawan, I.Y. Habibi, M.T. Daryon. 2006. Pemanfaatan Ekstrak Bawang Merah sebagai pengganti Rooton F untuk Menstimulasi Pertumbuhan Akar Stek Pucuk Jati (Tectona grandis L). Direktorat PKMP-1-8-1

Fahmi, Z.I. 2014. Kajiam Pengaruh Auksin Terhadap Perkecambahan Benih dan Pertumbuhan Tanaman Balai Besar Perbenihan Proteksi Tanaman Perkebunan. Surabaya.

Hamzah. 2016. Pengaruh Konsentrasi IBA (Indole Buteric Acid) Dan Lama Perendaman Terhadap Pertumbuhan Stek Tembesu (Fagraea pragrans Roxb). Sains Jurnal Vol. 18 No.1 (2016) . Universitas Jambi. Jambi.

Hariana, A. 2006. Tumbuhan Obat dan Khasiatnya. Seri 2 : hal. 19-20. Penebar Swadaya. Jakarta.

Haryadi, 2013.Pengukuran Luas Daun Dengan Metode Simpson. Anterior Jurnal. Vol.12 (2) : 1-5 (2013). Agroteknologi Fakultas Pertanian dan Kehutanan. Universitas Muhammadiyah. Palangkaraya. 
Irwanto.2001. Pengaruh Hormon IBA (Indole Buteric Acid) Terhadap Presentasi Jadi Stek Pucuk Meranti Putih (Shorea montigena). Skripsi Sarjana. Universitas Pattimura. Ambon

Jinus, E, Prihastanti dan S. Haryanti. 2012. Pengaruh Zat Pengatur Tumbuh RootUp dan Super GA Terhadap Pertumbuhan Akar Stek Tanaman Jabon (Anthocephalus cadamba). Jurnal Sains dan Matematika. Vol.20 (2) : 35-40 (2012). Fakultas Sains dan Matematika. Universitas Diponegoro. Semarang.

Kartikasari, D. 2007. Studi Pengusahaan Minyak Kayu Putih (Cajuputi oil) di PMKP Jatimunggul KPH Indramayu Perum Perhutani Unit III Jawa Barat dan Banten. Skripsi. Departemen Manajemen Hutan. Institut Pertanian Bogor. Tidak dipublikasikan.

Kartikawati, N.K.K., A. Rimbawanto, M. Susanto, L.Baskorowati dan Prastyono. Budidaya dan Prospek Pengembangan Kayu Putih (Melaleuca cajuputi). Dalam : Na'iem, M., Mahfudz dan S.B. Prabawa (editor). 2014. Badan Penelitian dan Pengembangan Kehutanan. Dirjen Bina Usaha Kehutanan.PT. Penerbit IPB Press.Bogor.

Maulidah, S. 2012. Struktur Pasar Minyak Kayu Putih (Melaleuca leucadendron Oil) (Jurnal). Di Dalam : Jurnal Manajemen Pemasaran Vol.5 No. 1, Malang, April 2010 : 9-13. Jurusan Sosial Ekonomi Pertanian Universitas Brawijaya. Malang.

Muswita, 2011. Pengaruh Konsentrasi Bawang Merah (Allium cepa L.) terhadap Pertumbuhan Stek Gaharu (Aquilaria malaccensis OKEN), (Jurnal). Di dalam : Penelitian Universitas Jambi Seri Sains. Vol. 13 : 15-20

Omon, MR, 2002, Pengaruh Hormon IBA terhadap Pertumbuhan Stek Shorea balangeran (Korth.) Burck pada Media Air di Rumah Kaca Loka Litbang Satwa Primata, Kalimantan Timur, Buletin Penelitian Kehutanan, vol. 14, nomor 1, hal 1- 11.

Perum Perhutani. 2013. Perhutani Fokus Garap Non Kayu. Majalah BINA. Edisi 30 Desember 2013/Th XIII. Perum Perhutani.Jakarta.

Purwitasari W., 2004. Pengaruh Perasan Bawang Merah (Allium ascalonicum L.) Terhadap Pertumbuhan Akar Stek Pucuk Krisan (Chrysanthemum sp). (biliografi). Jurusan Biologi Fakultas Matematika dan Ilmu Pengetahuan Alam Universitas Diponegoro. Semarang.

Rahardja,P.C dan Wiryanta, W. 2003. Aneka Cara Memperbanyak Tanaman. PT. Agromedika Pustaka. Tangerang.

Rizalinda, 2013. Respon Pertumbuhan Stek Pucuk Keji Beling (Strobilanthes crispus $\mathrm{Bl}$ ) dengan Pemberian IBA (Indole Butyric Acid) . Protobiont Vol. 2 (2) : 26-31

Santoso, B. 2011. Pemberian IBA (Indole Butyric Acid) Dalam Berbagai Konsentrasi Dan lama Perendaman Terhadap Pertumbuhan Stek Kepu (Sterculia foetida Linn). Skripsi Sarjana. Fakultas Pertanian. Universitas Sebelas Maret. Surakarta. 
Setyowati T., 2004. Pengaruh Ekstrak Bawang Merah (Allium cepa L) dan Ekstrak Bawang Putih (Allium sativum L) Terhadap Pertumbuhan Stek Bunga Mawar (Rosa sinensis L). JIPTUMMPP. Kota Batu.

Siskawati, Elly, Riza Linda, Mukarlina. 2013. Pertumbuhan Stek Batang Jarak Pagar (Jatropa Curcas L) dengan Perendaman Larutan Bawang Merah (Allium cepa L.) dan IBA (Indole Butyric Acid). Jurnal. Dalam : Protobiont. Vol. 2 (3) : $167-170$.

Siswanto, Usman, Nurmaini Diana Sekta, Atra Romeida. 2010. Penggunaan Auksin dan Sitokimin Alami pada Pertumbuhan Bibit Lada Panjang (Piper retrofractum Vahl.). (Jurnal). Di dalam : Tumbuhan Obat Indonesia Vol. 3. No. 2.

Sumadiwangsa, E dan Setyawan. 2005. Peningkatan produktivitas dan Kualitas HHBK. (Prosiding). Di dalam : Ekspose Hasil-Hasil Litbang hasil Hutan. Hal. 117-131, 2005.

Tuhu, PFS. 2008. Efek Analgetika Ekstrak Etanol Daun Kayu Putih (Meulaleuca Leucadendron L) Pada Mencit Jantan. Skripsi Sarjana. Fakultas Farmasi. Universitas Muhamadiyah. Surakarta.

Wibowo, A dan Susanto, A.S. 2014. Budidaya Kayu Putih Hasil Pemuliaan.. Puslitbang Perum Perhutani. Cepu.

Widyaningrum, D.U. 2002. Pengaruh Perlakuan Ukuran Umbi G0 dan B-Nine, Paclobutrazol, 2.4-D Terhadap Pertumbuhan dan Produksi Umbi Bibit Kentang G1 Kultivar Granola dalam Rumah Ketat Serangga. Skripi Sarjana. Jurusan Budidaya Pertanian. Fakultas Pertanian. Institut Pertanian Bogor. 